\title{
Bacillales XII
}

National Cancer Institute

\section{Source}

National Cancer Institute. Bacillales XII. NCI Thesaurus. Code C85917.

A bacterial family of uncertain placement in the phylum Firmicutes and the order Bacillales that is used to classify the genus Exiguobacterium. 